\title{
Mycobacterium abscessus
}

National Cancer Institute

\section{Source}

National Cancer Institute. Mycobacterium abscessus. NCI Thesaurus. Code C86533.

A species of aerobic, Gram positive, rod shaped bacteria assigned to the phylum

Actinobacteria. This species is acid-fast, nonmotile, does not reduce nitrate, is amidase, urease and nicotinamidase positive and benzamidase, isonicotinamidase, succinamidase and acetamidase negative. M. abscessus is a rapidly growing mycobacterium found in water, soil and dust, and can cause a variety of serious infections of the skin, soft tissues and lungs, especially in persons with chronic lung diseases. 